\title{
Preparation and properties of $(\mathrm{CdS})_{x}-(\mathbf{P b S})_{1-x}$ thin-film composites
}

\author{
L P DESHMUKH, B M MORE, S G HOLIKATTI and P P HANKARE \\ Department of Physics, University Centre for P.G. Studies, Shivaji University, Solapur \\ 413003, India
}

MS received 18 March 1994; revised 23 May 1994

\begin{abstract}
A modified chemical deposition process is employed for the preparation of thin-film $(\mathrm{CdS})_{x}-(\mathrm{PbS})_{1-x}$ composites with $0.2 \leqslant x \leqslant 0.8$. Cadmium sulphate, lead acetate and thiourea are used as the basic source materials. The electrical conductivity is found to decrease with increasing composition parameter $x$ up to 0.5 and increase for further increase in $x$. The composites are polycrystalline as is revealed from XRD and microscopic observations and show phases of both cubic and hexagonal $\mathrm{CdS}$, cubic $\mathrm{CdO}$ and $\mathrm{PbS}$, and tetragonal $\mathrm{PbO}$ and $\mathrm{PbO}_{2}$. Additional peaks of free elemental $\mathrm{Cd}$ and $\mathrm{S}$ have also been observed. For all the phases no significant variation in lattice parameters with $x$ has been observed. The optical absorption studies show the presence of four well-defined absorption edges at approximately $0.45 \mathrm{eV}, 1.05 \mathrm{eV}, 1.80 \mathrm{eV}$ and $2.35 \mathrm{eV}$, at the same energies for all $x$ values. The absorption coefficient is of the order of $10^{4} \mathrm{~cm}^{-1}$ and mode of band-to-band transition is of the direct type.
\end{abstract}

Keywords. Chemical deposition process; $(\mathrm{CdS})_{x}-(\mathrm{PbS})_{1-x}$.

\section{Introduction}

Sulphide and mixed sulphide thin-film coatings find extensive use in a number of electronic devices such as photoconductors, thin-film transistors, photodetectors, electroluminescent cells and photovoltaic devices including photoelectrochemical solar cells (Sood et al 1978; Martinuzzi et al 1980; Hall et al 1981; Gordillo 1985; Reddy et al 1987; Rodriguez and Gordillo 1989; Nair et al 1990; Morris and Vanderveen 1992). A large variety of deposition techniques and their hybrids have been utilized for producing these films. II-VI group compounds have a prominent place in this respect as they show high efficiency, high optical absorbance and direct band gaps corresponding to a wide solar spectrum (Razykov 1988). These systems form a continuous range of solid solutions that allow many of the physical properties to be controlled smoothly and the structural parameters to be optimized by changing the molar composition of the basic ingredients. Owing to the combination of these properties, thin-film heterostructures and multiple quantum-well structures based on these compounds are suitable for creating a number of optoelectronic devices (Razykov 1988).

This communication reports some of our experimental observations on optical and structural properties of chemically deposited $(\mathrm{CdS})_{x}-(\mathrm{PbS})_{1-x}$ thin-film composites.

\section{Experimental procedures}

The composite layers of $(\mathrm{CdS})_{x}-(\mathrm{PbS})_{1-x}$ with $x=0 \cdot 2-0.8$ were produced on optically plane glass substrates from the reaction bath comprising $\mathrm{Pb}^{2+}$ and $\mathrm{Cd}^{2+}$ ions present simultaneously. The salt solutions were mixed and then complexed with sufficient 
quantities of sodium hydroxide, aqueous ammonia and triethanolamine. Continuous addition of thiourea was made exterior to the deposition system. Chemomechanically cleaned glass substrates (attached to a specially designed substrate holder) were rotated in the reaction mixture with a $70 \pm 2 \mathrm{rpm}$ speed. The deposition time and temperature were $45 \mathrm{~min}$ and $85^{\circ} \mathrm{C}$ respectively and the resulting $\mathrm{pH}$ was around 11 (Deshmukh et al 1990; Deshmukh and More 1993).

The electrical conductivity of the composites was measured in the $300 \mathrm{~K}$ to $600 \mathrm{~K}$ temperature range for every $5^{\circ} \mathrm{C}$ rise and fall in temperature. The X-ray diffraction studies on these samples were carried out within a span of angles between $5^{\circ}$ and $100^{\circ}$ with a Philips PW-1710 X-ray diffractometer with $\mathrm{CuK}_{\alpha} \mathrm{X}$-radiation. The optical studies were performed on these samples with a spectrophotometer (Hitachi-330, Japan). The scanning wavelength range was $3500-26,000 \AA$. Microstructure was examined using a scanning electron microscope.

\section{Discussion}

The possibility of deposition of $(\mathrm{CdS})_{x}-(\mathrm{PbS})_{1-x}$ semiconducting thin composite layers in an aqueous medium is explored in this work. The deposition process and the electrical and optical properties of chemically deposited $\mathrm{CdS}$ and $\mathrm{PbS}$ films have been discussed in our recent communications (Deshmukh et al 1990, 1992; Deshmukh and More 1993). With PbS films, the history of the chemical deposition technique could be traced back (Hauser 1910) and the subsequent development in deposition process, characteristics and applications of chemically deposited $\mathrm{PbS}$ and $\mathrm{PbSe}$ films have been outlined by many workers (Bube 1960; Chopra et al 1982; Reddy et al 1987; Nair et al 1989, 1990; Deshmukh et al 1992; Deshmukh and More 1993). Most of the II-VI semiconductors have a more or less narrow photosensitivity region although they are highly photosensitive and therefore we shall confine our attention to a graded energy gap semiconductor system in which the energy gap is allowed to vary between the two energy gaps of the semiconducting materials. Such a system exhibits high photosensitivity over a wider spectral range so that a maximum amount of the incident sunlight can be converted into electric power. Considering the above facts, we have deposited $(\mathrm{CdS})_{x_{-}}-(\mathrm{PbS})_{1-x}$ thin-film composites for different values of the parameter $x$ by employing our newly developed modified chemical deposition process (Deshmukh et al 1990, 1992; Deshmukh and More 1993). The composites are smooth, highly adherent, uniform and densely packed, and almost nonreflecting. The colour of the deposit changes from orange red to yellowish orange to yellow to greyish yellow and finally to greyish black as $x$ is decreased from unity to zero. Initially the film growth proceeds at a constant rate and slowly the growth rate falls to zero resulting in a terminal thickness of a layer. The deposition parameters like $\mathrm{pH}$, temperature, speed of the substrate rotation, concentration, etc. play a vital role in deciding the growth rate, terminal thickness, quality of the deposit and many more properties of the composite layers obtained. In order to obtain a uniform composite layer throughout the thickness, the rate of formation of $\mathrm{CdS}$ and $\mathrm{PbS}$ should be the same and controlled during deposition. However compared to $\mathrm{Pb}^{2+}$ ions, $\mathrm{Cd}^{2+}$ ions, in general, have the tendency of reacting faster with $S^{2-}$ ions forming CdS. To avoid this, a sufficient amount of triethanolamine was used to slow down the rate of formation of CdS (Reddy et al 1987; Deshmukh and More 1993). $\mathrm{NaOH}$ was added 


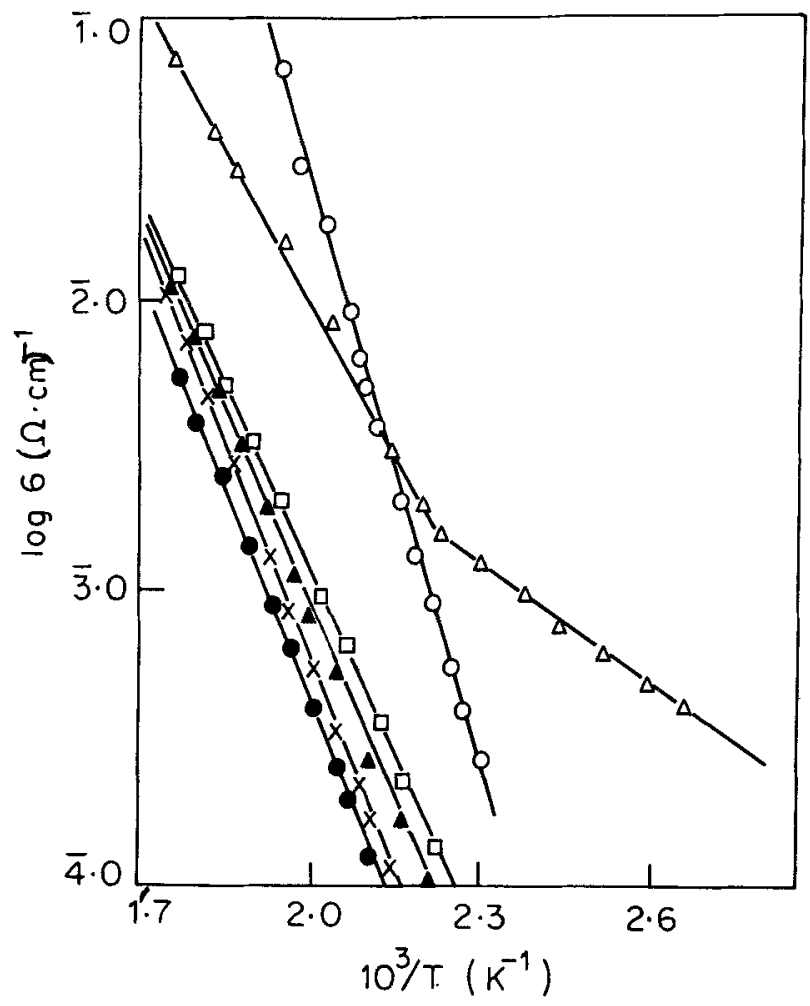

Figure 1. Temperature dependence of electrical conductivity for composite thin films with composition parameter $x=0.2(\square), 0.3(\Delta), 0.35(\times), 0.5(O), 0.65(\Delta)$ and $0.8(O)$.

as a complexing agent and ammonia solution to increase adherence of the deposits to the substrate.

The electrical conductivity of the composite layers has been measured in the 300-600 K temperature range. The temperature dependence of electrical conductivity is shown in figure 1 for five typical values of $x$. It has been found that the conductivity decreases systematically with increase in the composition parameter $x$ up to 0.5 which can be understood from the decrease in the grain size and therefore an increased amount of disorder in the sample during the growth process. At the grain boundaries there are a large number of defects because of incomplete atomic bonding which results in the formation of charge carrier trapping centres thereby reducing the electrical conduction. After being electrically charged, the traps produce a potential barrier reducing the mobility of the carriers. These observations are in good agreement with the results reported by Razykov (1988) on $(\mathrm{Zn} \mathrm{Se})_{x}(\mathrm{Cd} \mathrm{Te})_{1-x}$ and our earlier report on $(\mathrm{CdS})_{x}-(\mathrm{PbS})_{1-x}$ thin-film composite structures (Deshmukh and More 1993). For $x \geqslant 0.5$, conductivity increases with $x$ and this seems to be in contrast with the results reported by others. We propose the following explanation for this increased conductivity. Since $\mathrm{PbS}$ and $\mathrm{CdS}$ are deposited simultaneously, an increase in the $\mathrm{Cd}$ content in $(\mathrm{CdS})_{x}-(\mathrm{PbS})_{1-x}$ films leads to an increased amount of $\mathrm{CdS}$ formation that becomes Cd-rich for higher values of $x$ leading to an increased concentration of $\mathrm{S}$ vacancies and thus in free carrier density (Rodriguez and Gordillo 

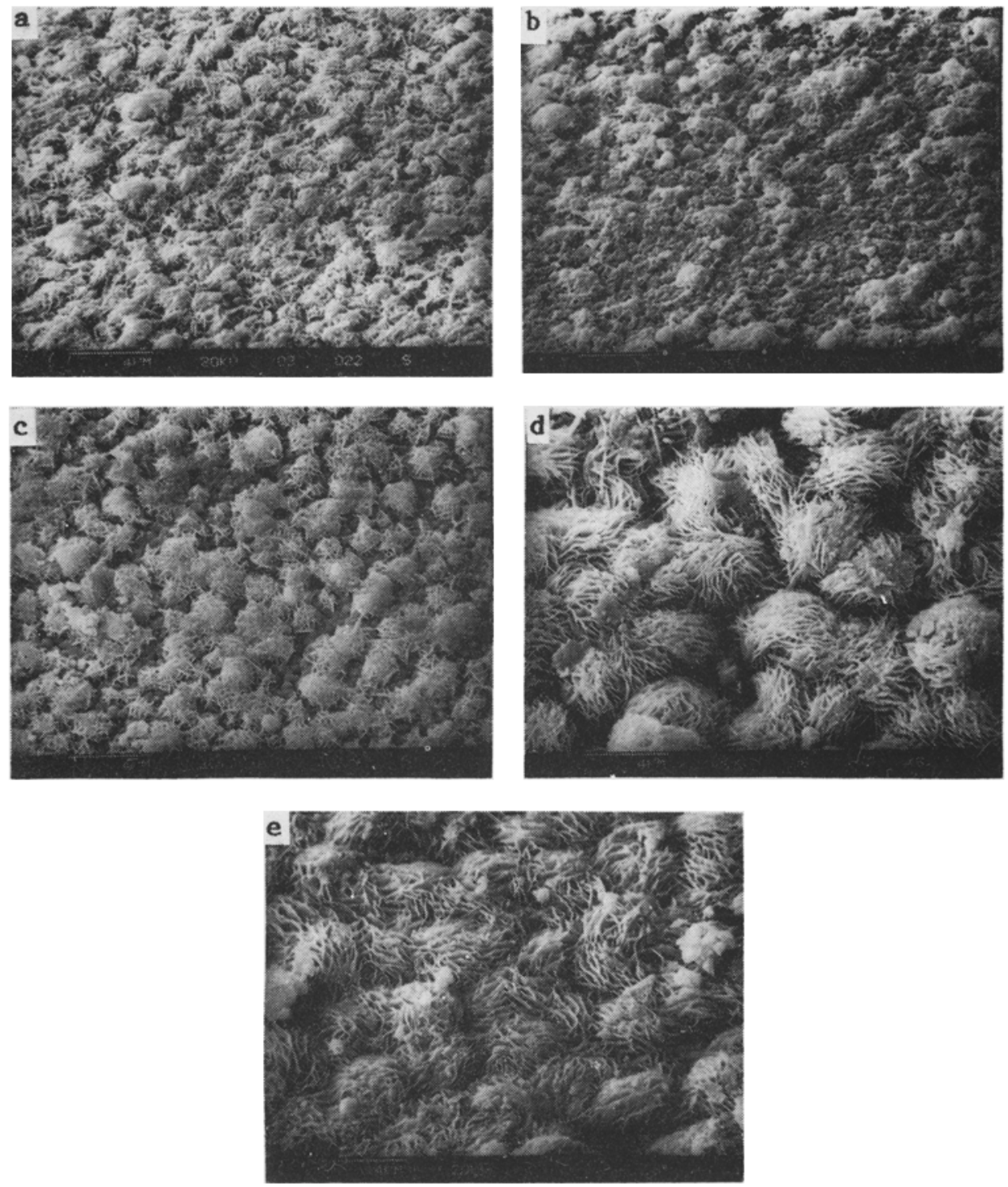

Figure 2. Scanning electron micrographs of five typical composites: (a) $x=0 \cdot 2$, (b) $x=0 \cdot 35$, (c) $x=0.5$. (d) $x=0.65$, and $\{\mathbf{e} ; x=0.8$.

1989: Deshmukh and More 1993). Secondly, at higher magnitudes of $x,(\mathrm{CdS})_{x^{-}}$ $(\mathrm{PbS})_{1-x}$ composite is CdS-dominating and will be more ordered contributing to the decreased grain boundary scattering effect which in turn increases the size of the grains and carrier mobility (Deshmukh and More 1993). The SEM micrographs also support the above observations (figure 2). An activation energy of electrical conduction has been determined from the slope of $\log 6$ vs $1 / T$ plot and its variation with the composition parameter $x$ in $(\mathrm{CdS})_{x}-(\mathrm{PhS})_{1-x}$ composite is shown in figure 3 . The $\mathrm{X}$-ray diffractograms of the as-deposited samples were obtained to determine the crystal structure and lattice constants. The deposits are polycrystals over the com- 


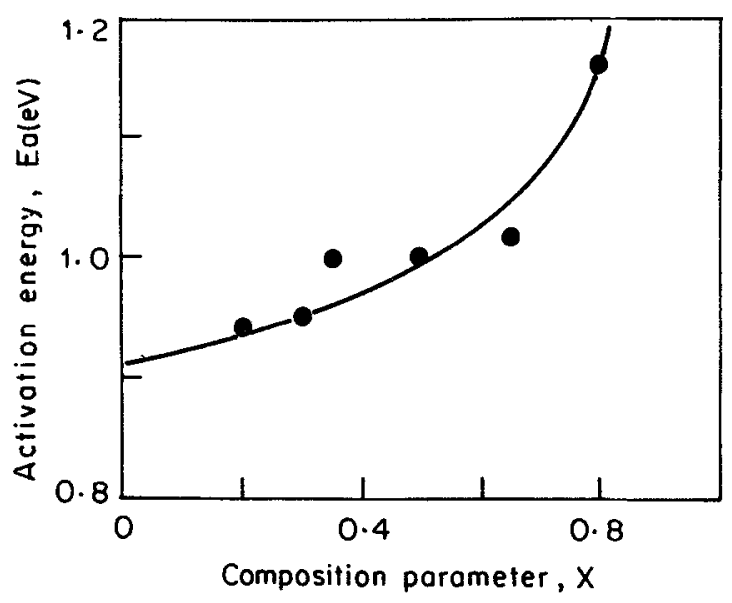

Figure 3. Variation of activation energy $\left(E_{\mathrm{a}}\right)$ with the composition parameter $(x)$.

Table 1. Analysis of the XRD studies of $(\mathrm{CdS})_{x}-(\mathrm{PbS})_{1-x}$ composites $(0 \cdot 2 \leqslant x \leqslant 0.8)$.

\begin{tabular}{|c|c|c|c|c|c|c|c|c|}
\hline \multirow{2}{*}{$\begin{array}{l}\text { Composition } \\
\text { parameter } \\
(x)\end{array}$} & \multirow{2}{*}{$\begin{array}{c}d \AA \\
\text { observed }\end{array}$} & \multirow{2}{*}{$\begin{array}{c}d \AA \\
\text { ASTM }\end{array}$} & \multicolumn{6}{|c|}{$h k l$ planes } \\
\hline & & & $\operatorname{CdS}(\mathrm{C})$ & $\mathrm{CdS}(\mathrm{H})$ & $\mathrm{PbS}(\mathrm{C})$ & $\mathrm{PbO}(\mathrm{T})$ & $\mathrm{PbO}_{2}(\mathrm{~T})$ & $\mathrm{CdO}(\mathrm{C})$ \\
\hline \multirow[t]{11}{*}{0.2} & 3.577 & 3.583 & - & 100 & - & - & - & - \\
\hline & $3 \cdot 362$ & $3 \cdot 360$ & 111 & - & - & - & - & - \\
\hline & $3 \cdot 362$ & $3 \cdot 357$ & - & 002 & - & - & - & - \\
\hline & 3.158 & $3 \cdot 160$ & - & 101 & - & - & - & - \\
\hline & 2.097 & 2.099 & - & - & 220 & - & - & - \\
\hline & $2 \cdot 061$ & 2.058 & 220 & - & - & - & - & - \\
\hline & $2 \cdot 061$ & 2.068 & - & 110 & - & - & - & - \\
\hline & 1.789 & 1.791 & - & 200 & - & - & - & - \\
\hline & 1.757 & 1.761 & - & 112 & - & - & - & - \\
\hline & 1.640 & 1.647 & - & - & - & - & 300 & - \\
\hline & $1-397$ & $1 \cdot 398$ & - & 203 & - & - & - & - \\
\hline \multirow[t]{17}{*}{0.3} & $3 \cdot 360$ & $3 \cdot 360$ & 111 & - & - & 一 & - & - \\
\hline & $3 \cdot 360$ & 3.357 & - & 002 & - & - & - & - \\
\hline & 3.050 & 3.035 & - & - & - & 111 & - & - \\
\hline & 2.928 & 2.919 & - & - & - & 002 & - & - \\
\hline & $2 \cdot 720$ & $2 \cdot 712$ & - & - & - & - & - & 111 \\
\hline & $2 \cdot 453$ & $2 \cdot 450$ & - & 102 & - & - & - & - \\
\hline & $2 \cdot 360$ & $2 \cdot 360$ & - & - & - & 210 & - & - \\
\hline & 2.069 & $2 \cdot 058$ & 220 & - & - & - & - & - \\
\hline & 2.069 & 2.068 & - & 110 & - & - & - & - \\
\hline & 1.786 & 1.791 & - & 200 & - & - & - & - \\
\hline & 1.769 & 1.761 & - & 112 & - & - & - & - \\
\hline & 1.720 & 1.714 & - & - & 222 & - & - & - \\
\hline & 1.646 & 1.647 & - & - & - & - & 300 & - \\
\hline & 1.461 & 1.453 & 400 & - & - & - & - & - \\
\hline & 1.395 & 1.398 & - & 203 & - & - & - & - \\
\hline & $1 \cdot 360$ & 1.362 & - & - & 331 & - & - & - \\
\hline & 1.326 & 1.327 & - & 211 & - & - & - & - \\
\hline
\end{tabular}


Table 1. (Continued)

\begin{tabular}{|c|c|c|c|c|c|c|c|c|}
\hline \multirow{2}{*}{$\begin{array}{l}\text { Composition } \\
\text { parameter } \\
(x)\end{array}$} & \multirow{2}{*}{$\begin{array}{c}d \AA \\
\text { observed }\end{array}$} & \multirow{2}{*}{$\begin{array}{c}d \AA \\
\mathbf{A S T M}\end{array}$} & \multicolumn{6}{|c|}{$h k l$ planes } \\
\hline & & & $\mathrm{CdS}(\mathrm{C})$ & $\mathrm{CdS}(\mathbf{H})$ & $\mathrm{PbS}(\mathrm{C})$ & $\mathrm{PbO}(\mathrm{T})$ & $\mathrm{PbO}_{2}(\mathrm{~T})$ & $\mathrm{CdO}(\mathrm{C})$ \\
\hline \multirow[t]{16}{*}{0.5} & 3.579 & 3.583 & - & 100 & - & - & - & - \\
\hline & 3.356 & $3 \cdot 360$ & 111 & - & - & - & - & - \\
\hline & $3 \cdot 356$ & $3 \cdot 357$ & - & 002 & - & - & - & - \\
\hline & $3 \cdot 156$ & 3.160 & - & 101 & - & - & - & - \\
\hline & 2.873 & 2.900 & 200 & - & - & - & - & - \\
\hline & $2 \cdot 440$ & $2 \cdot 450$ & - & 102 & - & - & - & - \\
\hline & $2 \cdot 390$ & $2 \cdot 349$ & - & - & - & - & - & 200 \\
\hline & 2.065 & 2.068 & - & 110 & - & - & - & - \\
\hline & 2.065 & $2 \cdot 058$ & 220 & - & - & - & - & - \\
\hline & 1.898 & 1.898 & - & 103 & - & - & - & - \\
\hline & 1.826 & 1.840 & - & - & - & 212 & - & - \\
\hline & $1 \cdot 757$ & 1.753 & 311 & - & - & - & - & - \\
\hline & 1.757 & 1.761 & - & 112 & - & - & - & - \\
\hline & $1 \cdot 726$ & 1.714 & - & - & 222 & - & - & - \\
\hline & 1.651 & 1.647 & - & - & - & - & 300 & - \\
\hline & $1 \cdot 395$ & $1 \cdot 398$ & - & 203 & - & - & - & - \\
\hline \multirow[t]{13}{*}{0.65} & 3.356 & $3 \cdot 36$ & 111 & - & - & - & - & - \\
\hline & 3.356 & $3 \cdot 357$ & - & 002 & - & - & - & - \\
\hline & $3 \cdot 173$ & $3 \cdot 160$ & - & 101 & - & - & - & - \\
\hline & $2 \cdot 453$ & $2 \cdot 450$ & - & 102 & - & - & - & - \\
\hline & 2.073 & 2.068 & - & 110 & - & - & - & - \\
\hline & 1.904 & 1.898 & - & 103 & - & - & - & - \\
\hline & 1.789 & 1.790 & - & - & 311 & - & - & - \\
\hline & 1.757 & 1.753 & 311 & - & - & - & - & - \\
\hline & 1.757 & 1.761 & - & 112 & - & - & - & - \\
\hline & 1.729 & 1.731 & - & 201 & - & - & - & - \\
\hline & $1 \cdot 399$ & 1.398 & - & 203 & - & - & - & - \\
\hline & $1 \cdot 358$ & 1.362 & - & - & 331 & - & - & - \\
\hline & $1 \cdot 326$ & $1 \cdot 327$ & - & 211 & - & - & - & - \\
\hline \multirow[t]{13}{*}{0.8} & 3.578 & 3.583 & - & 100 & - & - & - & - \\
\hline & $3 \cdot 360$ & 3.360 & 111 & - & - & - & - & - \\
\hline & 3.360 & $3 \cdot 357$ & - & 002 & - & - & - & - \\
\hline & 2.909 & 2.900 & 200 & - & - & - & - & - \\
\hline & $2 \cdot 440$ & $2 \cdot 450$ & - & 102 & - & - & - & - \\
\hline & 2.074 & 2.068 & - & 110 & - & - & - & - \\
\hline & 2.074 & 2.058 & 220 & - & - & - & - & 一 \\
\hline & 1.916 & 1.917 & - & - & - & - & - & 211 \\
\hline & 1.843 & 1.840 & - & - & - & 212 & - & - \\
\hline & 1.720 & 1.714 & - & - & 222 & - & - & - \\
\hline & 1.682 & 1.680 & 222 & - & - & - & - & - \\
\hline & 1.682 & 1.679 & - & 004 & - & - & - & - \\
\hline & 1.646 & 1.647 & - & - & - & - & 300 & - \\
\hline
\end{tabular}

positional range of interest (i.e. $x=0 \cdot 2-0.8$ ). Table 1 shows the analysis of the different peaks indicating the presence of phases of hexagonal and cubic $\mathrm{CdS}$, cubic $\mathrm{CdO}$ and $\mathrm{PbS}$, tetragonal $\mathrm{PbO}$ and $\mathrm{PbO}_{2}$, and free elemental cadmium and sulphur. It is interesting to note that the hexagonal phases of $\mathrm{CdS}$ increased while cubic phases of 
$\mathrm{PbS}$ decreased as $\mathrm{x}$ increased from 0.2 to 0.8 . Other phases of cubic $\mathrm{CdS}$ and $\mathrm{CdO}$ and tetragonal $\mathrm{PbO}$ and $\mathrm{PbO}_{2}$ remained more or less the same (Deshmukh and More 1993). The lattice constants of all the phases were determined from the X-ray data and are listed in table 2. The lattice constants fit well with their ASTM values. This clearly indicates that the thin films deposited for various $x$ values $(0.2 \times 0.8)$ are $(\mathrm{CdS})_{x}-(\mathrm{PbS})_{1-x}$ composites and not of the type $\mathrm{Cd}_{x} \mathrm{PbS}_{1-x}$. These observations are similar to those reported by Razykov (1988) and Reddy et al (1984).

The optical absorption spectra of these samples have been studied to evaluate the absorption coefficient in the solar spectral region. Figure $4(a, b)$ is a plot of $(\alpha h v)^{2}$ $v s$ photon energy, $h v$. The plot exhibits the presence of four well-defined absorption edges at the same energies for all $x$ values. The edges are found to be at $0.45 \mathrm{eV}$, $1.05 \mathrm{eV}, 1.80 \mathrm{eV}$ and $2.35 \mathrm{eV}$. The absorption edges at $0.45 \mathrm{eV}, 1.05 \mathrm{eV}$ and $1.8 \mathrm{eV}$ correspond to the fundamental optical transitions in $\mathrm{PbS}$, the optical band gaps of $\mathrm{PbS}, \mathrm{PbO}$ and $\mathrm{PbO}_{2}$ being $0.40 \mathrm{eV}, 1.0 \mathrm{eV}$ and $1.80 \mathrm{eV}$ respectively (Deshmukh and

Table 2. Lattice constants of different phases in $(\mathrm{CdS})_{x}-(\mathrm{PbS})_{1-x}$ with the composition parameter $x$.

\begin{tabular}{|c|c|c|c|c|c|c|c|c|c|}
\hline \multirow{2}{*}{$\begin{array}{l}\text { Composition } \\
\text { parameter } \\
(x)\end{array}$} & \multirow{2}{*}{$\begin{array}{c}\overline{\operatorname{CdS}(\mathrm{C})} \\
a(\AA)\end{array}$} & \multirow{2}{*}{$\begin{array}{c}\mathrm{CdS}(\mathrm{H}) \\
a(\AA)\end{array}$} & \multirow{2}{*}{$c(\AA)$} & \multicolumn{6}{|c|}{ Phases } \\
\hline & & & & $\mathrm{PbS}(\mathrm{C})$ & $\mathrm{CdO}(\mathrm{C})$ & $\mathrm{PbO}$ & 'etra) & $\mathrm{PbO}_{2}$ & etra) \\
\hline 0.2 & 5.825 & $4 \cdot 130$ & 6.722 & 5.932 & - & $\ldots$ & - & 4.941 & - \\
\hline 0.3 & 5.821 & $4 \cdot 139$ & 6.722 & 5.926 & 4.714 & 5.056 & 5.853 & 4.938 & - \\
\hline 0.50 & 5.827 & $4 \cdot 133$ & - & - & 4.679 & - & - & 4.838 & $3 \cdot 361$ \\
\hline 0.65 & 5.822 & $4 \cdot 137$ & 6.717 & 5.932 & - & - & - & - & - \\
\hline 0.8 & 5.822 & $4 \cdot 128$ & 6.725 & 5.938 & 4.694 & - & 5.820 & 4.938 & - \\
\hline ASTM & 5.818 & $4 \cdot 136$ & 6.713 & 5.93 & 4.696 & $\ldots$ & - & 4.941 & 3.379 \\
\hline
\end{tabular}

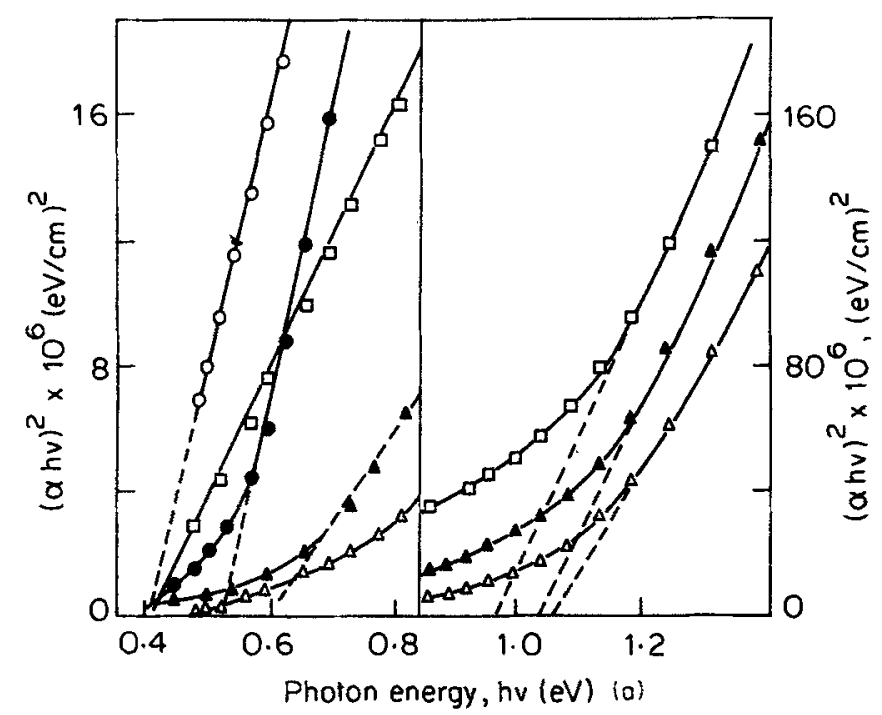

Figure 4. For caption, see p. 462. 


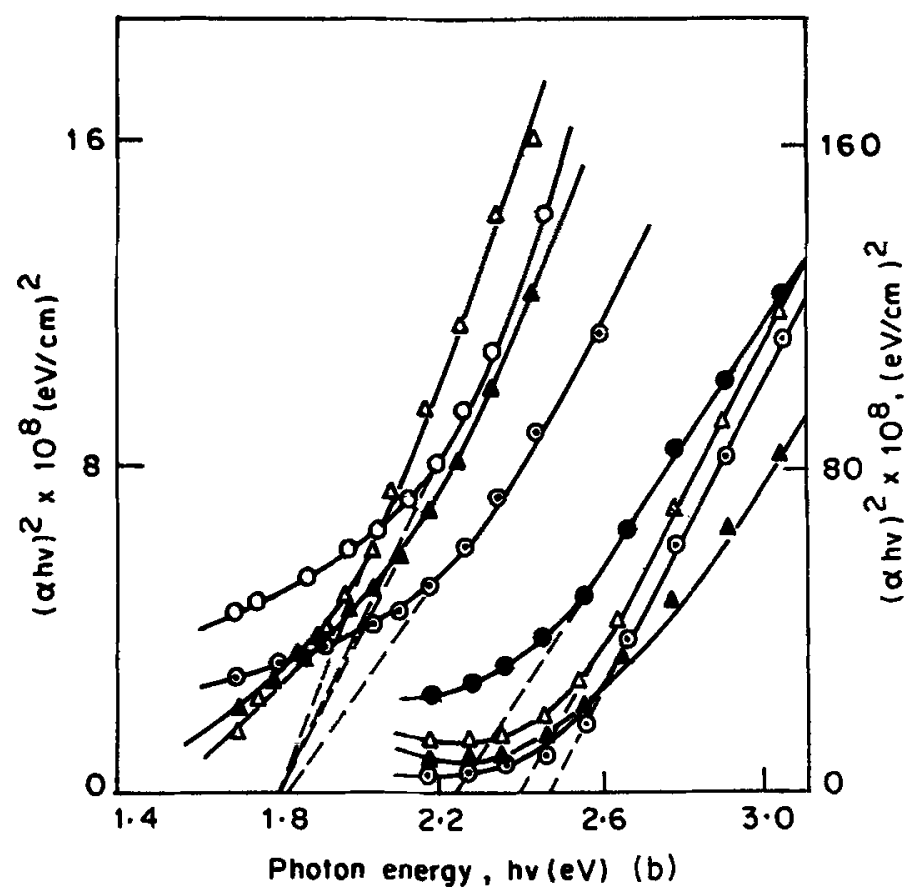

Figure 4. Determination of the optical band gaps for various thin-film composites. a. $x=0 \cdot 3$ $(\square), 0.35(\Delta), 0.5(\Delta), 0.65(O)$ and $0.8(\odot)$ and $b . x=0.3(\odot), 0.35(\Delta), 0.5(\triangle), 0.65(O)$ and $0.8(0)$.

More 1993). The XRD studies also support these observations. An absorption edge at $2.35 \mathrm{eV}$ corresponds to a fundamental optical transition in CdS. This contradicts the observations of Reddy et al (1987) wherein only two absorption edges (at $0.5 \mathrm{eV}$ and $1.7 \mathrm{eV}$ ) have been reported for fundamental transitions in PbS. Our XRD observations also reveal the presence of hexagonal and cubic phases of CdS. Further the absorption coefficients of both $\mathrm{PbS}$ and $\mathrm{CdS}$ in our case are comparable and therefore presence of an absorption edge at $2.35 \mathrm{eV}$ is obvious (Deshmukh and More 1993).

In the present investigation no continuous changes in lattice parameters and fundamental optical gap are observed. Thus our studies suggest that these films are of the $(\mathrm{CdS})_{x}-(\mathrm{PbS})_{1-x}$ composite type (Reddy et al 1987; Deshmukh and More 1993).

\section{Conclusions}

A modified chemical deposition process developed in our laboratory has been successfully used to deposit large-area $(\mathrm{CdS})_{x}-(\mathrm{PbS})_{1-x}$ thin-film composites. The films consist of multicomponent composite structures for the range of composition parameter studied as suggested by structural and optical studies. The coatings are polycrystals with the lattice parameters independent of the compositional parameter $x$. The fundamental transitions corresponding to both $\mathrm{CdS}$ and $\mathrm{PbS}$ are observed. Additional transitions at $1.05 \mathrm{eV}$ and $1.8 \mathrm{eV}$ are observed bacause of the oxide formation during the growth process. 


\section{Acknowledgement}

Authors would like to thank the Registrar, Shivaji University, Kolhapur, for the financial support under the unassigned UGC minor research grant.

\section{References}

Bube R H 1960 Photoconductivity of solids (New York: Wiley) p. 95

Chopra K L, Kainthala R C, Pandya D K and Thakoor A P 1982 Physics of thin films (eds) G Hass et al, (New York: Academic Press) Vol. 12 p. 201

Deshmukh L P and More B M 1993 Proc. int. conf. on energy, environment and electrochemistry (Karaikudi) p. 57

Deshmukh L P, Palwe A B and Sawant V S 1990 Solar Cells 28 1; also in 1990 Solar Energy Mat. 20341

Deshmukh L P, Zipre K V, Rane B P, Palwe A B, Hankare P P and Manikshete A H 1992 Solar Energy Mat. Solar Cells 28249

Gordillo G 1985 Solar Cells 14210

Hall R B, Birkmire R W, Phillips J E and Meaking J D 1981 Proc. 15th IEEE photovoltaic spec. conf. (Orlando) p. 777

Hauser O 1910 Chem. Z. 341079

Martinuzzi S, Sarti D, Vassilersky D and Zapien F 1980 Solar Cells 2173

Morris G C and Vanderveen R 1992 Solar Energy Mat. Solar Cells 26217

Nair P K, Nair M T S, Fernandez A and Ocampo M 1989 J. Phys. D : Appl. Phys. 22829

Nair P K, Ocampo M, Fernandez A, and Nair M T S 1990 Solar Energy Mat. 20235

Razykov T M 1988 Thin Solid Films 164301

Rodriguez J A and Gordillo G 1989 Solar Energy Mat. 19421

Reddy G B, Pandya D K and Chopra K L 1987 Solar Energy Mat. 15383

Sood A K, Wu K and Zemel J N 1978 Thin Solid Films 4873 